\title{
JOGOS AFRICANOS E O ENSINO DE POLINÔMIOS: UMA EXPERIENCIA EXTENSIONISTA COM O JOGO DARA ALGEBRICO
}

\section{AFRICAN GAMES AND THE TEACHING OF POLYNOMIALS: AN EXTENSIONIST EXPERIENCE WITH THE GAME ALGEBRAIC DARA}

Luiz Eduardo da Silva Santos* Anna Karla Silva do Nascimento**

Resumo: A inserção da "História e Cultura Afro-brasileira" no currículo escolar trouxe implicações pedagógicas no que tange à forma de trabalhá-la na disciplina de Matemática. Buscamos, então, verificar em que medida os jogos africanos podem contribuir com a aprendizagem matemática. O presente artigo apresenta impressões iniciais da ação de extensão "Jogos de origem africana e educação matemática: um olhar etnomatemático", vinculada à Universidade Federal do Cariri (UFCA) e realizada com alunos da educação básica da cidade de Brejo Santo - CE. Tal ação envolveu o levantamento de jogos de tabuleiro africanos que apresentassem potencial pedagógico e um processo de adaptação de um dos jogos para trabalhar um conteúdo curricular da Matemática. Esse estudo culminou na elaboração do Dara Algébrico, jogo que trata de polinômios e expressões polinomiais. A adaptação de jogos africanos foi satisfatória e possibilitou o andamento de outros trabalhos que envolvessem conhecimento matemático a partir de jogos africanos.

Palavras chave: Jogos Africanos; Matemática; Polinômios.

\begin{abstract}
The insertion of "Afro-Brazilian History and Culture" in the school curriculum has had teaching implications regarding the way of working while teaching the subject Mathematics. Therefore, this study seeks to ascertain the extent to which African games can contribute to mathematical learning. This article presents initial impressions of the extension action "Games of African origin and mathematical education: an ethnomathematical view", linked to the Federal University of Cariri (UFCA) and carried out with basic education students from the city of Brejo Santo - CE. This action involved the survey of African board games that presented pedagogical potential and a process of adaptation of one of the games to work a curricular content of Mathematics. This study resulted in the elaboration of the Algebraic Dara, a game dealing with polynomials and polynomial expressions. The adaptation of African games was satisfactory and allowed the progress of other works involving mathematical knowledge from African games.
\end{abstract}

Keywords: African Games; Mathematics; Polynomials. 


\section{Introdução}

$\mathrm{Na}$ educação básica, o ensino da História do Brasil se baseia no reconhecimento da contribuição das mais variadas culturas e etnias na construção da população brasileira, o que inclui a africana. Com a obrigatoriedade do ensino da História e Cultura AfroBrasileira e Indígena no currículo das escolas, disciplinas específicas da área de Ciências Humanas (História, Geografia, Sociologia) e Linguagens e Códigos (Artes, Literatura) foram foco dessa inclusão. Tal medida auxiliou para que as referências culturais apresentadas aos alunos fossem ampliadas e, de certo modo, contribuíssem para mudanças na visão de mundo e na formação de identidades mais plurais (BRASIL, 2013).

A implantação dessa dimensão multicultural no currículo da educação básica permite, segundo as Diretrizes Curriculares Nacionais Gerais da Educação Básica, "o reconhecimento da riqueza das produções culturais e a valorização das realizações de indivíduos e grupos sociais [...]" (BRASIL, 2013, p. 115). Quando se trata do currículo escolar de Matemática, essa perspectiva aparenta ser mais difícil de alcançar. Como alternativa, o uso de jogos de tabuleiro mostra-se como uma oportunidade de contextualizar a cultura africana.

Embora o primeiro pensamento que se tem a respeito de jogos é de entretenimento e diversão, estes permitem outra função que é a educativa, pois, ao mesmo tempo em que existe uma ludicidade, um prazer de jogar, existe também a aquisição de um conhecimento, ainda que implicitamente. A proposta de desenvolver no aluno um entendimento através de um jogo não envolve distrair, mas sim instruir, introduzindo, aprofundando ou preparando-o para a assimilação de um conhecimento, exigindo um pensamento mais detalhista, com a elaboração de estratégias e ações baseadas no seu conhecimento adquirido.

A proposta apresentada neste artigo surgiu da possibilidade de introduzir a temática "História e Cultura Afro-brasileira" no contexto da disciplina de matemática e analisar como os jogos de origem africana poderiam contribuir para o ensino de conteúdos matemáticos. Com tal interesse, deu-se início ao projeto de extensão intitulado "Jogos de origem africana e Educação Matemática: um olhar etnomatemático", vinculado à Pró-Reitoria de Extensão da Universidade Federal do Cariri (UFCA). Partindo de pesquisas de caráter bibliográfico e com o levantamento de diversos jogos de origem no continente africano, o estudo se voltou para a adaptação de um jogo em função de conteúdos pertencentes à matriz curricular de matemática dos anos finais do ensino fundamental. Então, iniciou-se uma abordagem de campo com o desenvolvimento de atividades junto a alunos de uma escola da rede de ensino básica da cidade de Brejo Santo (CE).

\section{A pluralidade cultural e a utilização de jogos}

Dispositivos como a Lei 10.639/2003 consideram a importância do reconhecimento da história e cultura africana na área educacional, apresentando-se como ações afirmativas na tentativa de reparar acontecimentos históricos e buscando o combate ao racismo e à discriminação (BRASIL, 2003, s.p.). A repercussão didático-pedagógica trazida por essa lei requisitou que as relações étnico-raciais fossem repensadas como objeto de estudo. Então, se fez necessária a criação de procedimentos pedagógicos que pudessem englobar a temática tornada obrigatória, promovendo o reconhecimento da pluralidade cultural - temática trazida pelos Parâmetros Curriculares Nacionais -, que "diz respeito ao conhecimento e à valorização das características étnicas e culturais dos diferentes grupos sociais que convivem no território nacional [...]" (BRASIL, 1997, p. 121).

A produção cultural mediada pela tradição transmitida a cada geração permite o acesso e conhecimento de algumas singularidades de grupos sociais que podem não possuir registros históricos (escritos e visuais), permitindo, por exemplo, a reconstituição de memórias presentes em jogos e brincadeiras. Tratar de elementos da cultura africana em sala de aula e envolvê-los de conceitos matemáticos através de jogos africanos objetiva proporcionar momentos de aprendizagem que utilizem os jogos enquanto recursos didáticos. Dessa forma, é possível ter contato com diferentes culturas e, além de tudo, absorver conteúdos matemáticos inseridos nessas propostas.

Assim, conforme Santos (2008), "os jogos, provavelmente, deveriam ser utilizados antes ou imediatamente após a introdução de um novo conceito [...]" (SANTOS, 2008, p. 29). Porém, é importante salientar que não é a aplicação de um jogo a parte principal do processo, mas sim a ação provocada nos alunos diante de uma situação de protagonista e o que eles agregam em termos de conhecimento. Portanto, ao assumir uma nova posição, o aluno quebra o ciclo no qual geralmente é o professor quem realiza todos os processos de uma aula (leitura, interpretação, solução e compreensão de situações-problemas) sem permitir uma discussão.

De acordo com os Parâmetros Curriculares Nacionais de Matemática, os jogos se configuram como "um objeto sociocultural em que a Matemática está presente [...]", e jogar é "uma atividade natural no desenvolvimento dos processos psicológicos básicos, pois supõe um 'fazer sem obrigação externa e imposta', embora demande exigências, normas e controle [...]" (BRASIL, 1998, p. 47). Por possuir essa característica sociocultural, os jogos podem ser usados como base para a temática Pluralidade Cultural, levando em conta que: 
[...] um currículo de Matemática deve procurar contribuir, de um lado, para a valorização da pluralidade sociocultural, evitando o processo de submissão no confronto com outras culturas; de outro, criar condições para que o aluno transcenda um modo de vida restrito a um determinado espaço social e se torne ativo na transformação de seu ambiente. (BRASIL, 1998, p. 28).

Portanto, existe uma possibilidade de romper a imagem de que o conhecimento matemático foi construído exclusivamente por um determinado grupo social, além de envolvê-lo com aspectos históricos do saber matemático ao longo do tempo e da diversidade provocada pelo multiculturalismo. Assim, podem-se visualizar oportunidades "para construção e evolução dos conceitos e como um elemento de integração da Matemática com o tema Pluralidade Cultural." (BRASIL, 1998, p. 33).

Da perspectiva da Etnomatemática - "um programa de pesquisa em história e filosofia da matemática, com óbvias implicações pedagógicas" (D'AMBROSIO, 2005, p. 27) -, pode-se dizer que os aspectos da matemática em diversos contextos culturais são peças importantes no entendimento da produção de saberes de origem africana quando vistos de uma ótica histórica e social. A Etnomatemática se configura, então, como:

[...] uma tentativa de descrever e entender as
formas pelas quais ideias, chamadas pelos
etnomatemáticos de matemáticas, são
compreendidas, articuladas e utilizadas por outras
pessoas que não compartilham da mesma
concepção de "matemática". Ela tenta descrever o
mundo matemático do etnomatemático na
perspectiva do outro. [...] A Etnomatemática, de
fato, cria uma ponte entre a matemática e as ideias
(e conceitos e práticas) de outras culturas.
(BARTON, 2006, p. 55).

Ao analisar documentos educacionais e pretendendo observar como as relações entre cultura africana e Matemática podem ocorrer, vê-se, por exemplo, que as Orientações e Ações para Educação das Relações Étnico-Raciais sugerem as disciplinas de artes e matemática na proposta de incorporar a história e a cultura negra em sala de aula, sendo que a matemática pode explorar aspectos da geometria presentes nas figuras e atuar na perspectiva do trabalho com as formas e as medidas (BRASIL, 2006, p. 185). Já as propostas referentes à matriz africana dentro da Base Nacional Curricular Comum (BNCC) se limitam às áreas de Artes e Educação Física e levam em conta apenas o caráter lúdico e o desenvolvimento de capacidades nos alunos por meio da experimentação e do resgate (BRASIL, 2017).

Por outro lado, este artigo busca mostrar que a Matemática pode usufruir da história e cultura africana como ponto de partida para aulas no ensino fundamental, especialmente no diz respeito à utilização de jogos de origem africana. Pois, em conformidade com Souza (2016), mesmo que a Lei 10.639/03 induza que o ensino da temática História e Cultura Afrobrasileira se faça em determinadas disciplinas, especificamente aquelas da área de Ciências Humanas, "o ensino da Matemática oferece um campo fértil para a promoção da diversidade étnico-racial nos ambientes escolares." (SOUZA, 2016, p. 13).

\section{Dara : um potencial jogo de origem africana}

O Dara é um jogo de tabuleiro que possui conceitos matemáticos e trabalha com alinhamento de peças e arranjos. Dessa forma, o uso desse tipo de jogo é importante para o desenvolvimento do raciocínio lógico-matemático e, por ser de origem africana, permite apresentar parte da história africana, na tentativa de reconstruir o pensamento matemático na África e investigar mais aspectos matemáticos dos jogos tradicionais.

Para Smole, Diniz e Milani (2007), o trabalho com jogos, quando devidamente planejado e executado, contribui significativamente com a aprendizagem dos alunos, pois auxilia no "desenvolvimento de habilidade como observação, análise, levantamento de hipóteses, busca de suposições, reflexão, tomada de decisão, argumentação e organização, as quais são estreitamente relacionadas ao raciocínio lógico [...]" (SMOLE; DINIZ; MILANI, 2007, p. 9). Optou-se, então, por aqueles que envolvem princípios estratégicos e matemáticos, como jogos de alinhamento, entre os quais estão: o Dara (Nigéria), Shisima (Quênia), Achi (Gana), Murabaraba (Lesoto) Seega (Egito), e jogos Mancalas (GERDES; DJEBBAR, 2011).

O jogo utilizado durante a ação de extensão foi o Dara (Figura 1), um jogo de origem nigeriana jogado pelo povo Dakarki. Também pode ser chamado de Derrah ou Doki (“cavalo", na língua haussa ${ }^{1}$ )

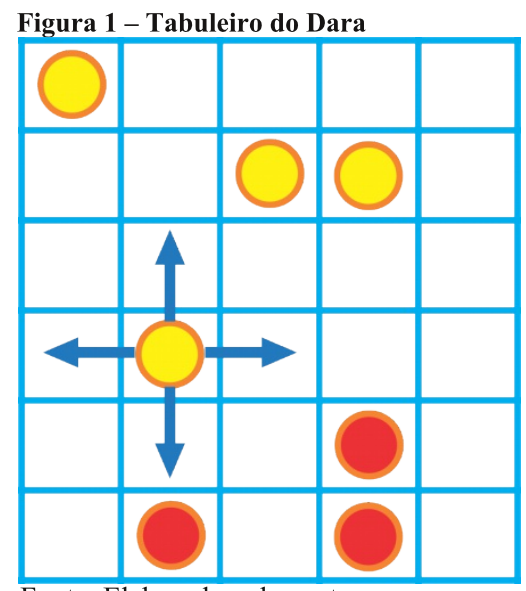

Fonte: Elaborado pelos autores

É bastante popular no norte da Nigéria, Níger, Mali e outras regiões que compõem a África do Norte. Podem-se usar pedrinhas como peças e pode ser jogado em um tabuleiro com cinco linhas e com seis colunas, parecido com um tabuleiro de damas 
(GIORDANI; RIBAS, 2015).

De acordo com Zaslavsky (2000), historicamente, os bons jogadores de Dara sempre foram muito prestigiados e, após o trabalho diário, os campeões viajavam de tribo em tribo desafiando os jogadores locais. Os campeonatos podiam durar tanto quanto os jogadores estivessem dispostos a jogar e os conhecimentos e estratégias dos campeões eram ensinados aos filhos assim que estes tivessem idade suficiente para começar a aprender como jogar.

O Dara é um jogo de estratégia para dois jogadores ou duas equipes e, alternadamente, cada jogador posiciona uma peça de cada vez no tabuleiro até completar o total das 24 peças (MALFATO, 2012).

Provenzo e Junior (1981) acrescentam que:

[...] o jogo é jogado em duas fases, envolve o planejamento estratégico e a concentração necessária para bloquear e manobrar seu oponente. O objetivo é desenvolver o raciocínio lógico, efetuar a captura e bloqueio das peças do adversário com atenção e concentração (PROVENZO; JUNIOR, 1981, p. 157).

Decidido quem começa o jogo, o jogador movimentará suas peças para casas adjacentes vazias nos sentidos para frente, para trás e para os lados, mas nunca nas diagonais. Ao conseguir alinhar três de suas peças, o jogador terá o direito de eliminar uma peça adversária.

Outras regras do jogo dizem que: os jogadores não devem ter mais de três peças alinhadas em nenhum momento do jogo; um alinhamento feito no início do jogo (na primeira fase) não vale quando as peças ainda estão sendo colocadas; a cada alinhamento feito, somente uma peça deverá ser retirada, ainda que sejam feitas mais de uma linha naquele mesmo momento; o jogo termina quando um dos jogadores não puder fazer mais nenhum alinhamento (ZASLAVSKY, 2000).

Usar os jogos de origem africana levou em conta os possíveis problemas matemáticos que o jogo propõe e a análise de possibilidades de como usá-los em aulas de matemática. Sendo assim, é possível perceber um conhecimento sobre arranjo de peças, memória e concentração que foram base para a adaptação detalhada a seguir.

\section{Aspectos metodológicos}

Para a realização desta ação de extensão, adotou-se uma metodologia inicial de procedimentos bibliográficos, pesquisando-se materiais já publicados em meio eletrônico, livros e revistas para o levantamento de jogos de origem africana que apresentassem possível potencial para trabalhar conteúdos da disciplina de matemática. Tal levantamento levou em consideração, principalmente, o tipo de jogo: jogos de alinhamento e captura, posicionamento estratégico, movimento e alinhamento, movimento e bloqueio. Feita a classificação e escolhido o jogo Dara, aspectos técnicos foram estudados para como inseri-lo na disciplina de matemática e quais procedimentos pedagógicos seriam necessários. Isso implicou num processo de adaptação para incorporar um conteúdo de matemática no jogo, mas sem negar sua essência (regras e história).

Além das atividades matemáticas que poderiam ser desenvolvidas mediante a construção dos tabuleiros, foi proposta uma adaptação para o ensino de polinômios. Para isso, as peças foram confeccionadas com monômios escritos e as regras apresentadas na seção anterior continuariam valendo ainda assim. Conforme o objetivo do jogo (alinhar três peças), o jogador deve organizar os monômios pelo grau, separá-los por parênteses e prosseguir com o próximo passo para definir as operações a serem usadas na expressão (Figura 2).

Figura 2 - Peças utilizadas no tabuleiro, formação de um alinhamento e transcrição dos monômios
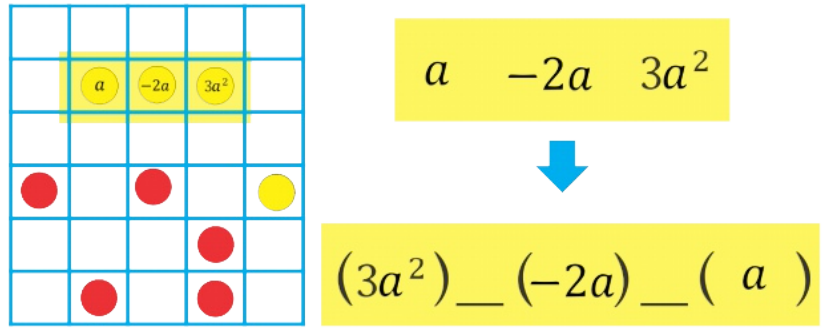

Fonte: Elaborado pelos autores.

As operações a serem realizadas entre os monômios são determinadas com o uso de dados especiais (Figura 3): dados que possuem aparência tabular e formado por duas faces - uma colorida e outra branca. Jogam-se os dados; ao caírem com uma das faces, geram-se combinações que, de acordo com o quadro da Figura 3, definirão as operações que o jogador utilizará.

Figura 3 - Dados e quadro de operações usados na formação das expressões algébricas

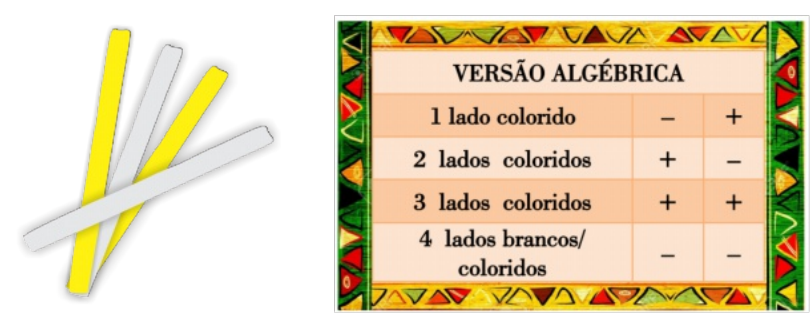

Fonte: Elaborado pelos autores.

Cada combinação possível de ser obtida está organizada no quadro (Figura 3), indicando operações que devem ser feitas com os monômios alinhados no tabuleiro pelo jogador. Como exemplo: se após o alinhamento das peças mostradas na Figura 2, o jogador lançasse os dados e obtivesse duas faces coloridas e duas faces brancas, isso significaria que, na 
expressão, ele deverá somar o primeiro monômio com o segundo e entre o segundo e o terceiro monômio deve haver uma subtração. A Figura 4 ilustra essa exemplificação.

\section{Figura 4 - Resultado do lançamento dos dados e formação da expressão final a ser calculada}

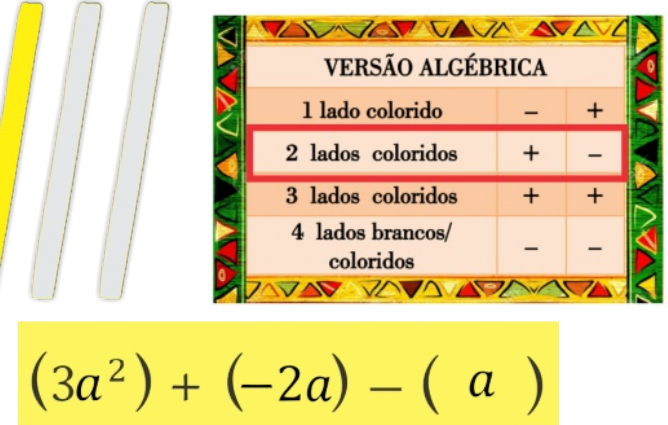

Fonte: Elaborado pelos autores

O próximo passo é a resolução da expressão formada e isso envolve a eliminação dos parênteses e operações com termos semelhantes, de forma a tornar a expressão a mais reduzida possível (Quadro 1). Caso o jogador não consiga calcular, perderá uma de suas peças. Se acertar, retirará uma peça do adversário.

Quadro 1 - Resolução da expressão polinomial

$$
\left(3 a^{2}\right)+(-2 a)-(a)=3 a^{2}-2 a-a=3 a^{2}-3 a
$$

Fonte: Elaborado pelos autores.

Concluído o estudo teórico e de catalogação dos jogos, partiu-se para os procedimentos de planejamento e organização da ação: construir uma atividade que tivesse como objetivo contextualizar os jogos de tabuleiro africano como produções culturais daquele continente e sua utilização no ensino de matemática. A execução desta ação teve como universo de estudo alunos de uma escola da rede de ensino fundamental municipal da cidade de Brejo Santo, estado do Ceará - a Escola de Ensino Fundamental Professora Maria Heraclides Lucena Miranda. A amostra participante é composta por alunos do $8^{\circ}$ ano do Ensino Fundamental, numa turma com 25 estudantes, na faixa etária entre 13 e 14 anos de idade.

Dois encontros foram feitos na turma citada. No primeiro encontro, apresentou-se a proposta aos alunos e iniciou-se a confecção dos tabuleiros do jogo escolhido - o Dara (Figura 5). Nessa etapa, prezou-se pelo acompanhamento dos alunos, discutindo-se formas de construir o tabuleiro e explorando sua geometria, de modo que pudessem visualizar e descrever relações geométricas simples a partir dessa tarefa.

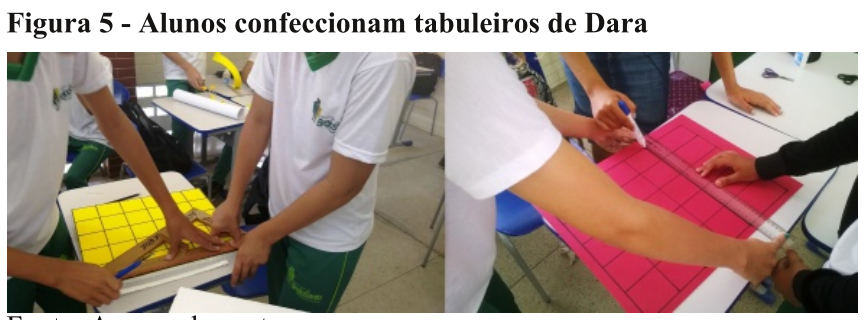

Fonte: Acervo dos autores.

O segundo encontro consistiu na apresentação da temática "História e Cultura Afro-brasileira" para os alunos, dialogando sobre a legislação vigente e sobre orientações pedagógicas existentes para sua implantação. Feita a abordagem histórica, teórica e procedimental do jogo, realizaram-se as primeiras partidas.

Como forma de coleta de dados, foi utilizada a técnica da observação, que de acordo com Lakatos e Marconi (2003, p. 191): "É um elemento básico da investigação científica, utilizada na pesquisa de campo [...]" e "obriga o investigador a um contato mais direto com a realidade". Optou-se por uma observação sistemática, na qual "o observador sabe o que procura e o que carece de importância em determinada situação" (LAKATOS; MARCONI, 2003, p. 192). Durante a manipulação dos tabuleiros e das peças, prosseguiu-se com uma metodologia de observação participante, ao se desenvolver "a partir da interação entre pesquisadores e membros das situações investigadas" (PRODANOV; FREITAS, 2013, p. 67).

Além do procedimento de observação e acompanhamento dos participantes, optou-se pela aplicação de um questionário "constituído por uma série ordenada de perguntas, que devem ser respondidas por escrito" (MARCONI; LAKATOS, 2003 , p. 201). Partiu-se de questões gerais para questões específicas, aspecto defendido por Prodanov e Freitas (2013), que explicam que "o questionário deve ser objetivo, limitado em extensão e estar acompanhado de instruções que expliquem a natureza da pesquisa" (PRODANOV; FREITAS, 2013, p. 108). Após os encontros e a coleta de dados, foi necessária a análise dos questionários e dos relatos de campo, de forma a evidenciar opiniões e expectativas dos alunos participantes.

\section{Resultados e discussão}

Nesta seção, estão as impressões percebidas com base na aplicação do jogo Dara Algébrico, pontuadas de acordo com as etapas realizadas junto com os alunos participantes. Durante a construção dos tabuleiros, viu-se uma oportunidade de começar trabalhando a geometria característica daquele jogo de tabuleiro. Ainda que formas de construir tivessem sido sugeridas, as principais dificuldades dos alunos em relação à construção do tabuleiro estavam na criação de uma estratégia própria para desenhá-lo e no 
manuseio da régua. Embora, tradicionalmente, a geometria lide mais com uma mecanicidade, voltada principalmente para a reprodução de figuras, esta prática inicial partiu de uma atividade mecânica para uma atividade dinâmica, de modo que os alunos estavam submetidos a diversos questionamentos que os mantinham motivados a prosseguir $(\mathrm{O}$ que fazer para dividir um retângulo em 42 quadrados pequenos? Como posso dividir os segmentos uniformemente?

etc.). Nesse processo, percebeu-se uma ativa participação dos alunos e que a exploração individual da atividade proporcionou um momento mais interativo entre os grupos. A interação aluno-aluno apontou que uma metodologia lúdica pode favorecer uma aprendizagem mais significativa.

Depois dessa etapa, apresentaram-se as regras do jogo, mas, compreendendo que sua assimilação realmente se faria durante a manipulação, passou-se para a prática. Mediante o surgimento de dúvidas, os alunos eram orientados com exemplos ilustrados e projetados no quadro branco para melhorar a compreensão das regras.

$\mathrm{Na}$ etapa de formação das expressões polinomiais, os alunos sentiram algumas dificuldades no momento de organizá-las e reduzi-las, mas que não os impediram de prosseguir, pois, conforme o professor regente, aquele conteúdo já havia sido apresentado aos alunos. Assim, viu-se que o jogo pode significar "uma atividade de resolução de problemas [...]" e "que desencadeia a construção de novos conceitos ou ideias matemáticas, de forma motivadora, prazerosa e desafiadora" (RIBEIRO, 2008, p. 22).

Embora as operações entre os monômios fossem simples (soma e subtração), muitos alunos pecavam ao somar os expoentes dos termos, gerando expressões incorretas. Tendo em vista essas dificuldades, a orientação era que os alunos analisassem melhor em quais situações se poderia operar entre os termos da expressão, recorrendo e relembrando propriedades algébricas simples, mas que poderiam estar confusas no momento. Assim, observa-se que a elaboração de atividades baseadas em jogos nas aulas de matemática deve definir claramente os objetivos que os alunos devem alcançar, além de considerar os recursos, a adequabilidade das atividades e quais passos serão feitos pelos alunos.

Pela quantidade de etapas e regras, muitos grupos não conseguiram concluir as partidas do jogo, mas ressalta-se também a pouca participação das duplas durante a resolução das expressões, ficando a resolução somente para um dos alunos. O tempo destinado à prática do jogo dependeu do tempo disponível dos alunos (110 minutos). A duração da atividade não influenciou severamente no desempenho dos alunos, mas alguns grupos necessitaram de mais tempo para concluir as jogadas. Outros grupos, por outro lado, aproveitaram bem o tempo disponibilizado e conseguiram terminar.

As limitações na resolução das expressões polinomiais foram contornadas com a ajuda dos aplicadores, orientando os alunos a construírem os cálculos de forma clara e ordenada. Com base em registros de campo, observou-se que a eficiência do jogo em introduzir e trabalhar os polinômios foi aumentando conforme os alunos iam manipulando-o, e o diálogo entre as duplas favoreceu bastante esse aumento.

Em função dos questionários aplicados com a turma e observando-se a recorrência de respostas dadas, foi possível aferir as expectativas, as impressões deixadas pelos encontros e as dificuldades que os alunos sentiram.

Levando em conta a avaliação subjetiva e individual feita pelos alunos nos questionários, verificou-se que as dificuldades que os alunos afirmaram ter ao manusear os jogos foram na manipulação dos sinais e na falta de estratégias para a resolução das expressões polinomiais. Considerou-se compreensíveis as dificuldades apontadas para entender as regras, já que era a primeira vez que tinham contato com o jogo. Quando questionados sobre o que poderia ser melhorado no jogo e na sua aplicação, os alunos apontaram a clareza dos objetivos e um melhor acompanhamento junto aos alunos que, entretanto, eram numerosos.

Sobre as contribuições deixadas pelos encontros e se conseguiram aprender ou relembrar algum conteúdo relacionado à matemática, os alunos responderam que foi um momento em que exercitaram o que já vinham aprendendo, pois de acordo com o professor regente, o conteúdo ministrado naquele momento era o mesmo presente no jogo. Outras respostas afirmavam que foi possível relembrar conteúdos esquecidos, aperfeiçoando algumas técnicas de cálculo de operações básicas, reforçando o que tinham aprendido de uma maneira mais interativa.

Ao tentar identificar se os alunos foram capazes de observar a matemática dentro do jogo, percebeu-se que muitos deles foram capazes de relacionar o conteúdo apresentado com aquele visto anteriormente em sala de aula, indicando que o Dara Algébrico conseguiu ser mesclado à disciplina de matemática de forma conveniente.

Acerca das regras apresentadas para a aplicação dos jogos, os alunos opinaram, havendo certo equilíbrio nas respostas: aqueles que afirmavam ser complicadas, diziam também que os passos eram demorados, embora poucos tenham dado sugestões do que poderia mudar. Em contrapartida, outra parte afirmou serem regras fáceis, mas ainda assim, demoradas.

Ao opinarem sobre o uso do jogo novamente, a grande maioria dos alunos afirmou que gostaria de jogar outra vez e que recomendaria a outros alunos, justificando que é uma boa ferramenta para exercitar a aprendizagem em matemática; incentiva a tentar até aprender mais; possibilita o uso de um conteúdo visto normalmente em sala de aula; diverte, ao mesmo 
tempo em que reforça o que já sabem; aprendem de forma mais interativa e ajuda a melhorar o raciocínio.

Percebeu-se, então, que práticas metodológicas diversificadas trazem mais dinamicidade às aulas se comparadas a exposições orais e resoluções de atividades baseadas no conteúdo. Assim, o estímulo ao desafio provoca momentos de reflexão nos quais é necessário que se levantem estratégias para depois testá-las e verificá-las, de forma que a criatividade, a visão crítica e o desenvolvimento do raciocínio lógico sejam favorecidos.

\section{Considerações finais}

O "aprender Matemática" pode ser muitas vezes tido como difícil ou até mesmo complexo. Isso decorre do modo como ela é trabalhada e apresentada para os alunos. Nesse contexto, o que pode ser feito é trabalhar para alcançar o conhecimento construtivo, aquele que, mediante a participação ativa do aluno, provoca melhor absorção de informações. E para se chegar a esse objetivo necessita-se, cada vez mais, criar novas práticas que rompam com o tradicionalismo e o tratamento mecânico da Matemática. Esse é um ponto exposto por Resende e Mesquita (2013), ao afirmarem que "o ensino da matemática não se pode fundamentar apenas nas teorias; há que criar novas práticas no decorrer do tempo e evoluir objetivamente na direção do conhecimento construtivo" (RESENDE; MESQUITA, 2013, p. 203).

Ao fim da aplicação do jogo Dara Algébrico, foi possível perceber que a tentativa de aliar jogos de origem africana com o ensino de conteúdos da matriz curricular de matemática no ensino fundamental é alcançável. Tal perspectiva abre portas para outras pesquisas e o trabalho na adaptação de outros jogos com a mesma finalidade. Averigua-se que construir uma sequência de atividades que envolvem cultura africana e jogos é uma ótima possibilidade de trabalhar a temática "História e Cultura Afro-brasileira" dentro da matemática, que naturalmente não se mostra tão aberta a um tratamento de conteúdos de cunho cultural.

O Dara apresenta-se como um jogo simples, no entanto, o processo de adaptação para o ensino de polinômios requisitou dos discentes determinadas habilidades, como a atenção na resolução de cálculos algébricos e, principalmente, conhecimentos matemáticos acumulados de outros anos do Ensino Fundamental. Inicialmente, foi perceptível uma moderação por parte dos alunos, o que vem naturalmente do pouco contato com atividades desse tipo, resultando em partidas demoradas e certo estranhamento pela proposta, mas que foram contornadas, pouco a pouco, conforme adquiriam uma maior segurança.

O jogo veio, então, contribuir para a melhoria do olhar algébrico dos alunos, que estão comumente acostumados à resolução de situações problemas do livro didático que geralmente são feitas unicamente pelo professor. O uso do Dara desperta bem mais do que as habilidades matemáticas esperadas nos alunos. Além da aprendizagem incentivada pelas atividades, verificou-se a contribuição para o reconhecimento de articulações entre a herança cultural africana e o contexto da disciplina de Matemática. Verifica-se, então, a possibilidade do uso de jogos africanos como recursos educativos, auxiliando tanto na fixação de conteúdos de matemática quanto no reconhecimento e na valorização das contribuições culturais deixadas por outros povos.

\section{Referências}

BARTON, B. Dando sentido a etnomatemática: Etnomatemática fazendo sentido. In: RIBEIRO, J. P. M.; DOMITE, M. C. S.; FERREIRA, R. Etnomatemática: papel, valores e significado. São Paulo: Zuok, 2006.

BRASIL. Base Nacional Curricular Comum. Ministério da Educação. Brasília: MEC, 2017. Disponível em: $<\mathrm{http}$ ://basenacionalcomum.mec.gov.br/images/BNCC_publ icacao.pdf $>$. Acesso em: 18 dez. 2017.

BRASIL. Diretrizes Curriculares Nacionais Gerais da Educação Básica. Ministério da Educação. Secretária de Educação Básica. Diretoria de Currículos e Educação Integral. Brasília: MEC, SEB, DICEI, 2013. Disponível em:<http://portal.mec.gov.br/docman/julho-2013pdf/13677-diretrizes-educacao-basica-2013-pdf/file>. Acesso em: 17 dez. 2017.

BRASIL. Lei $\mathbf{n}^{\circ} \mathbf{. 1 0 . 6 3 9}$, de 9 de janeiro de 2003. Altera a Lei no 9.394, de 20 de dezembro de 1996, que estabelece as diretrizes e bases da educação nacional, para incluir no currículo oficial da Rede de Ensino a obrigatoriedade da temática "História e Cultura Afro-Brasileira", e dá outras providências. Brasília, DF, 2003. Não paginado. Disponível em:

$<$ http://www.planalto.gov.br/ccivil_03/leis/2003/L10.639.ht m>. Acesso em: 17 dez. 2017.

\section{BRASIL. Orientações e Ações para Educação das}

Relações Etnico-Raciais. Ministério da Educação,

Secretaria da Educação Continuada, Alfabetização e Diversidade. Brasília: SECAD, 2006. Disponível em: $<$ http://portal.mec.gov.br/dmdocuments/orientacoes_etnicor aciais.pdf $>$. Acesso em: 17 dez. 2017.

BRASIL. Secretaria de Educacãa Fundamental. Parâmetros curriculares nacionais: pluralidade cultural. Brasília: MEC/SEF, 1997. Disponível em:

$<$ http://portal.mec.gov.br/seb/arquivos/pdf/livro101.pdf $>$. Acesso em: $18 \mathrm{dez} .2017$

BRASIL. Secretaria de Educação Fundamental. Parâmetros curriculares nacionais: matemática. Brasília: $\mathrm{MEC} / \mathrm{SEF}$, 1998. Disponível em:

$<$ http://portal.mec.gov.br/seb/arquivos/pdf/matematica.pdf>. Acesso em: 18 dez. 2017.

D'AMBROSIO, U. Etnomatemática: Elo entre as tradições e a modernidade. 2. ed. Belo Horizonte: Autêntica, 2005.

GERDES, P.; DJEBBAR, A. History of Mathematics in Africa: AMUCHMA 25 Years. Lulu, Morriville. Vol. 1 (1986-1999), 2011.

GIORDANI, L. F.; RIBAS; R. P. Jogos lógicos de tabuleiro: jogos de bloqueio e alinhamento. Universidade Federal do Rio Grande do Sul, 2015. Disponível em: $<$ http://www.inf.ufrgs.br/lobogames/wp-

content/uploads/2015/09/jogos modulo1 texto.pdf $>$.

Acesso em: 20 dez. 2017. 
LAKATOS, E. M.; MARCONI, M. de A. Fundamentos de metodologia científica. 5. ed. São Paulo: Atlas, 2003.

MALFATO, I. C. Jogos Africanos: alternativa metodológica para o desenvolvimento do raciocínio lógico e propagação desta cultura. Universidade Estadual do Oeste do Paraná, 2012. Disponível em:

$<$ http://www.diaadiaeducacao.pr.gov.br/portals/cadernospde /pdebusca/producoes pde/2012/2012 unioeste mat pdp isa bel cristina malfato.pdf>. Acesso em: $20 \mathrm{dez} . \overline{2} 017$.

PRODANOV, C. C.; FREITAS, E. C. Metodologia do trabalho científico: métodos e técnicas da pesquisa e do trabalho acadêmico. 2. ed. Novo Hamburgo: Feevale, 2013. Disponível em: $<$ http://www.faatensino.com.br/wpcontent/uploads/2014/11/2.1-E-book-Metodologia-doTrabalho-Cientifico-2.pdf>. Acesso em: 21 dez. 2017.

PROVENZO, A. B.; JUNIOR, E. F. P. Jogue novamente, jogos de tabuleiro históricos que você pode fazer e jogar. Prentice-Hall, Inc., 1981.

RESENDE, G.; MESQUITA, M. G. B. Principais dificuldades percebidas no processo ensino-aprendizagem de matemática em escolas do município de Divinópolis, MG. EM TEIA Revista de Educacão Matemática e

Tecnológica Iberoamericana, Recife-PE, v. 3, n. 3, 2012.

Disponível em:

$<$ https://revistas.pucsp.br/index.php/emp/article/view/9841>

. Acesso em: 19 dez. 2017.
RIBEIRO, F. D. Jogos e modelagem na educação matemática. Curitiba: Ibpex, 2008.

SANTOS, F. L. F. A Matemática e o Jogo: influência no rendimento escolar. 2008. Dissertacão (Mestrado em Ciências da Educação - especialidade em Educação e Desenvolvimento) - Faculdade de Ciências e Tecnologia, Universidade Nova de Lisboa. Lisboa, 2008.

SMOLE, K. S.; DINIZ, M. I.; MILANI, E. Cadernos do

Mathema: Jogos de Matemática de $6^{\circ}$ a $9^{\circ}$ ano. Porto Alegre: Artmed, 2007

SOUZA, A. C. F. Jogos africanos e o currículo da matemática: uma questão de ensino. Dissertação (Mestrado Profissional em Rede Nacional) - Instituto de Biociências, Letras e Ciências Exatas, Universidade Estadual Paulista, São José do Rio Preto, 2016.

ZASLAVSKY, C. Jogos e atividades matemáticas do mundo inteiro. Tradução Pedro Theobald. Porto Alegre: Art Med, 2000.

\author{
Notas \\ ${ }^{1}$ É uma das mais importantes línguas africanas, falada em grande \\ extensão no continente africano.
}

